\title{
Designing for sensing, sensibilities, and sense-making
}

\section{Carol Strohecker}

105 Lower Rathmines Road

No. 103, Dublin 6, Ireland

E-mail: Carol.Strohecker@gmail.com

\begin{abstract}
During recent decades, miniaturisation and affordability of silicon chips have led to pervasiveness of devices for computation and communication. Now sensing technologies are becoming smaller and cheaper, and therefore more widely available to augment capabilities of mobile computational devices. These capabilities pose new challenges in designing tools and experiences for learning. Three experimental devices address such challenges as they enable collecting information from physical and social environments, and reflecting on its implications in personal and public spheres: 'Nature Trailer' is a locationaware story and decision-making tool for hikers; 'Smoke Rings' detects environmental tobacco smoke and projects potential consequences of prolonged exposures; and 'TexTales' co-opts cameras and mobile telephones as tools for developing public opinion.
\end{abstract}

Keywords: sensors; mobile computing; learning tools; learning environments; constructivity design; multimodal representations; intermodal literacies.

Reference to this paper should be made as follows: Strohecker, C. (2005) 'Designing for sensing, sensibilities, and sense-making', Int. J. Knowledge and Learning, Vol. 1, No. 3, pp.269-285.

Biographical notes: Carol Strohecker was Director of the Everyday Learning research group at Media Lab Europe (MLE), the European research partner of the Massachusetts Institute of Technology's (MIT) Media Laboratory. Prior to joining MLE, Carol worked in the USA at MERL - Mitsubishi Electric Research Laboratories and in the Human Interface Group of Sun Microsystems. She earned the PhD in Media Arts and Sciences (MAS) from MIT in 1991, and the MS in Visual Studies in 1986. She has been a Lecturer for MAS and a member of its Visiting Committee as an MIT Presidential Appointee. Carol contributes to various research-related boards and international programme committees, and has been a Fellow of the Harvard University Graduate School of Design, the US National Endowment for the Arts, and the Massachusetts Council for the Arts and Humanities. She holds four US patents for her work in interactive media tools and methods.

\section{Introduction}

As computational devices have become increasingly pervasive, they also have become increasingly mobile, making possible new forms of personal learning and challenging our expectations of the environments where learning can happen. The limited power, bandwidth, memory, and display resolution of portable devices pose additional 
challenges in designing for constructive learning. We are inventing mobile tools based on Constructionist ideas (Harel and Papert, 1991), so that in using the tools people not only receive information, but actively engage it to construct meanings for themselves - to the point that some entity results which did not exist before. In this view, learning is inherently a creative process. Supporting it means designing so that others can design: they generate things in the world along with ideas in the mind (Kafai and Resnick, 1996).

The work described here considers the design and development of such tools from both research and technology perspectives. From the perspective of learning research, a person's constructions are evidence of what and how she thinks. Phases of a constructed object's iterative production indicate changes in the thinking that gives rise to it, an emergence which in its character and depth may constitute a process of learning. Researchers can gain access to this thinking both through involvement in the situation of the object's production and through developing a relationship with the learner/producer. Ultimately, several kinds of evidence supplement the constructed object, e.g., researchers' accounts and self-reports may take the forms of conversational statements and gestures, and written and photographic documentation (Papert, 1980; Turkle, 1984; Strohecker, 1996).

From the perspective of tool-building, learners' early involvement in generating the tools and their situations of use is beneficial for developing the research relationships and promoting the learning, as well as generating optimal tool designs (Schön, 1983; 1992; Winograd et al., 1996). Our aim to support creative processes reframes familiar approaches to designing tools and systems with humans 'in the loop': what we once thought of as 'interface design' became 'interaction design,' then 'interactivity design' and 'experience design' - but now constructivity design addresses the design of tools that people can use to create their own designed objects, which are socially situated, personally meaningful, and therefore useful in processes of learning (Garrett, 2002; Jacobson, 1999; Shedroff, 2001; Strohecker and Slaughter, 2001; Strohecker and Butler, 2004).

\subsection{Pervasiveness of sensing technologies}

In designing tools for learning, we are also acknowledging the increasing availability of sensing technologies and people's increasing uses of mobile devices. About two decades ago, a phenomenon was beginning which made the revolution in computing technologies inevitable: silicon chips were becoming smaller and smaller, and more and more affordable. Today a comparable phenomenon is emerging: now sensing technologies are becoming smaller and more affordable. We are accustomed to tools with built-in sensors for light and sound (cameras and microphones), but now a wider range of sensors - including chemical detectors and instruments useful in healthcare - are becoming part of accoutrements such as handheld computers, cell phones, wristwatches, and clothing. Detection capabilities once available only to a small number of scientists and practitioners are now becoming widely available (Strohecker and Ananny, 2003). More and more people will be able to sample and study phenomena such as kinetics and kinesiology; environmental qualities of water, air and soil; and aspects of personal physiologies relevant to nutrition, respiration, and circulation. 


\subsection{New design challenges}

However, the sensed data will be widely used only if we can invent ways to represent them as information that people can understand and manipulate. This need challenges conventions in representational design, at the same time as increasing capabilities of computing devices offer new representational possibilities. Even very small devices can now support rich text, audio, and colourful moving images, and such modal capabilities continue to improve. Some devices can also support haptic inputs and outputs (Oakley and O'Modhrain, 2003; O'Modhrain, 2004). Information designers can consider how to represent ideas not only through a single output mode but also through combinations of modes, as well as through variations of stylistic treatments.

Further, it is not only designers who can work with such potentials but also the users of computing devices themselves, who can effect multimodal representations for their own expressive and communicative purposes. Just as people during medieval times developed a sophisticated visual literacy by 'reading' narratives rendered in the stained glass of cathedral windows, and just as others developed an 'intermodal' literacy through different ways of combining images and texts in the captioned illustrations of newspapers and magazines, users can develop complex literacies as they assign metadata to their digital photos, annotate their home movies, illustrate and voice-record commentary for their presentations, and create other composite media forms (Benjamin, 2004/1936; Berger, 1990/1973; Dondis, 1973; Strohecker, 2004).

The comic artist Scott McCloud has articulated a range of ways in which pictures and words can work together (McCloud, 1993; Taylor et al., 2004). For example, in image-word combinations, the two forms may, in their own way, express the same meaning, or they may express complimentary ideas that contribute to a more complex meaning. 'Distributing the load' among multiple channels becomes a strategy for effective communication and a challenge in representational design.

Considering this challenge from the perspective of designing tools and environments for learning, recalls the adage that you don't really understand something unless you understand it in more than one way. By representing ideas multiply, through various modalities and modal combinations, we can provide means for people to deepen their understandings of the represented data and ideas (Resnick et al., 2000; Strohecker and Slaughter, 2000). Further, multiple representations can provide avenues for different individuals, who inevitably have varying thinking styles, to enter and engage the ideas: having multiple 'ways in' increases the likelihood that a given thinker will find suitable ways to work with the represented ideas.

This point both stems from and informs methods for an overarching research agenda concerned with elucidating diversity in human thinking and learning. 'Thinking styles' may be characterised, in part, by preferences for representations that address visual, sonic, and haptic sensoria at varying levels of detail and through varying combinations. Such new representational capabilities may help to broaden the framing of 'styles' and interrelations among factors such as cognition, affect, and perception (Turkle and Papert, 1990; Lewkowicz, 1999; Picard et al., 2004). 


\subsection{Situated experiences}

Many writers have emphasised the importance of context to human action and communication (e.g., McLuhan, 1964; Birdwhistell, 1970; Lakoff and Johnson, 1980; Suchman, 1987). Similarly, the meaningfulness of sensed data depends on the situations in which the data are gathered as well as on how they are represented. Information and representations that are relevant to one time and place may not be to another, even if both situations are relevant to use of the tool. And importantly, from the perspective of learning and meaning-making, people need time to create and to think. Incidental encounters may spark curiosity, but deep and lasting learning develops through sustained engagement, reflection, and discussion.

Three experimental sensing devices illustrate strategies for collecting data from physical and social environments and for reflecting on the implications in personal and public spheres. 'Nature Trailer' combines location-aware sensing capabilities to provide information and stories for hikers; 'Smoke Rings' detects environmental tobacco smoke and projects potential consequences of prolonged exposures; and 'TexTales' co-opts cameras and mobile telephones as tools for developing public opinion.

\section{Nature Trailer}

'Nature Trailer' combines a handheld computer, a 'portable weather station,' and a desktop application to provide information and enhance appreciation of a locale. The multipart system informs hikers' decision-making and aids later contemplation of the hiking experience as well as planning of potential return visits (Donovan et al., 2003; 2004; Wood et al., 2004).

The hiker wears a backpack equipped with an anemometer (or wind vane), a solar radiation sensor, and a leaf wetness sensor (Figure 1). The anemometer protrudes from the top of the pack and spins according to the speed and direction of the wind. The small solar radiation sensor is attached to the back of the pack, where it is exposed to direct sunlight in the visible and ultraviolet ranges. The leaf wetness sensor is also attached to the outside back of the pack, where it can sense mist and rain. These sensors detect changes in the environment that will also be apparent to the user, such as a gust of wind or the onset of rain. The backpack contains a computer chip to process all the signals and a Bluetooth module to communicate with the handheld device.

In addition to Bluetooth support, the handheld computer includes a Global Positioning System (GPS) module and a digital compass (Figure 2). The interface also displays readings from the suite of weather sensors, maps, and a 'virtual sundial.' The sundial visualises the length of day and solar time, based on Greenwich Mean Time (GMT) and compensated by the current latitude and longitude obtained from GPS (Figure 3a).

Maps of the location show icons to indicate points of interest (Figure 3b). Clicking an icon triggers a short audio clip that suggests what is in that location. Such murmurs help hikers decide where to go along the trail. Upon arrival at a particular location, the hiker can hear the full version of the episode with the physical scene as the backdrop. This full rendition reflects current weather conditions: if it is raining on the hiker, then it will be raining on the story characters too. 
Figure 1 Nature Trailer's 'portable weather station' includes an anemometer (or wind vane), a solar radiation sensor, and a leaf wetness sensor. The backpack also contains a computer chip to process all the signals and a Bluetooth module to communicate with the partnered handheld device.

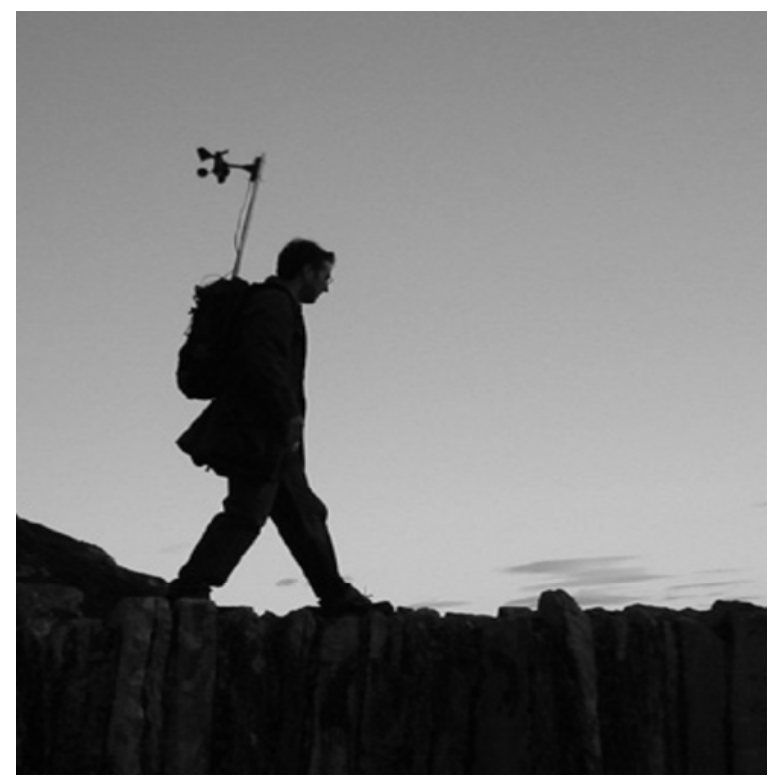

Figure 2 A digital compass on the handheld computer augments display of readings from the suite of weather sensors. The handheld device also includes Bluetooth support and a Global Positioning System (GPS) module, and the interface can further display maps of the site and a 'virtual sundial.'

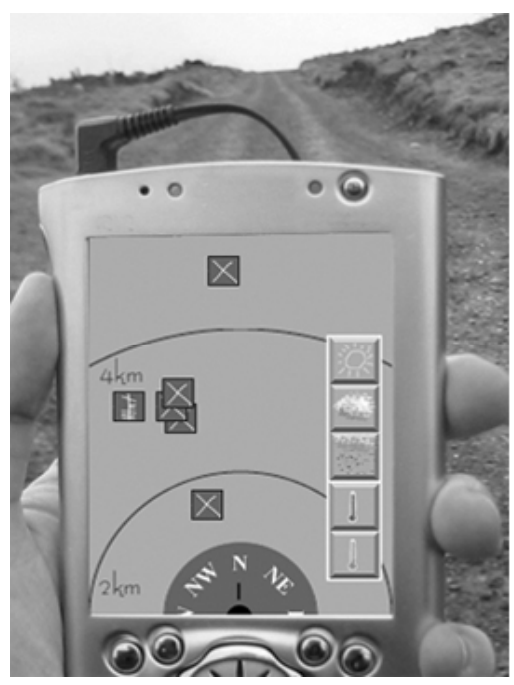


Figure 3 (a) The sundial's 24-hour clock shows hours of nighttime darkness through shading and daylight hours through the bright region. The 'shadow' cast from the centerpoint indicates the local solar time. This visualisation of the current time and length of the day are based on Greenwich Mean Time (GMT), compensated by the GPS report of the current latitude and longitude. (b) Icons indicate points of interest on maps of the site. Clicking an icon triggers a short audio clip that suggests features of that location and aids hikers in deciding where to go along the trail.

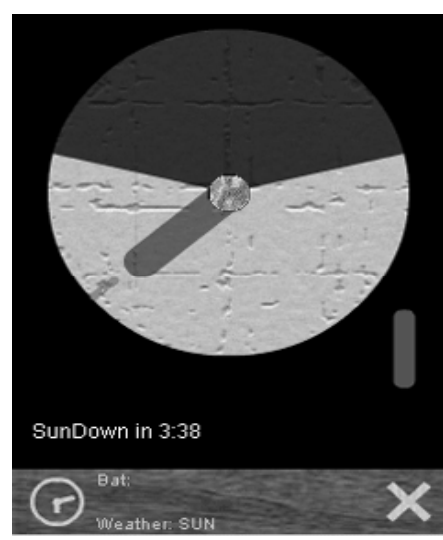

(a)

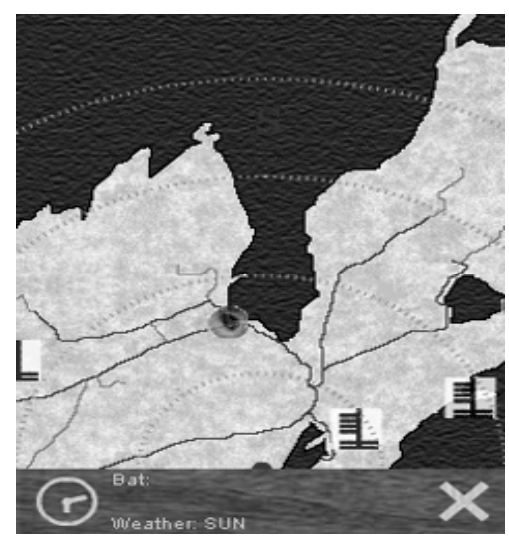

(b)

During the hike, the handheld computer maintains a log file documenting the GPS, compass, weather, and story information associated with each location visited. After the hike, in more relaxed surrounds, the hiker can upload the log to a desktop system and use it as a basis for reflecting on the experience. The map at the post-hike interface shows the dynamic progression of the hiker's particular route and enables replaying story episodes. In the current version, the GPS trail replays dynamically on a map of the area (Figure 4). Video versions of the audio episodes heard in the field play at the corresponding locations on the map (Figure 5). Hikers can also annotate the associated map, query locations not visited, and build potential routes for later explorations.

Figure 4 The hiker can upload a log of the GPS, compass, weather, and story information to a desktop system for revisiting and reflecting on the experience. The map at the post-hike interface shows the dynamic progression of the recorded route and enables replaying story episodes in video form. Hikers can also annotate the map, query new locations and build potential routes for later explorations.

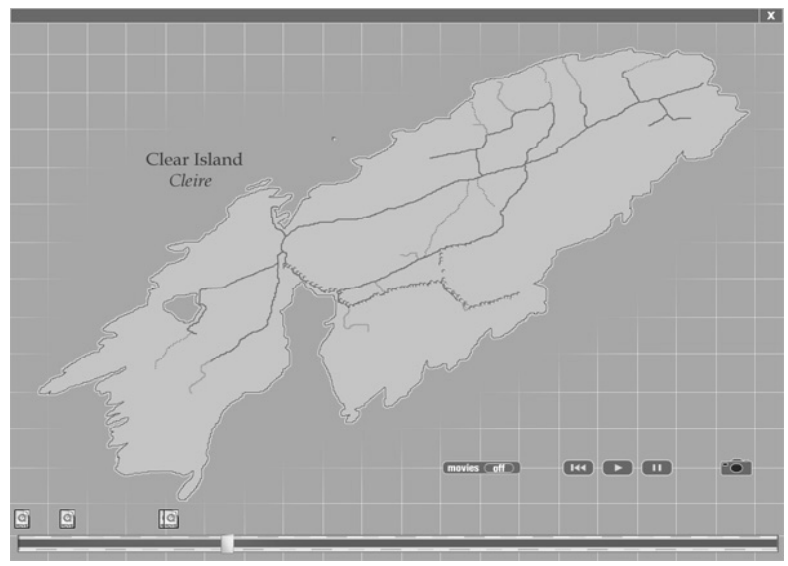


Figure 5 As the hiker relives the walk, story episodes heard along the way in shorter and longer audio forms now play in full video, completing the experience and potentially enhancing knowledge of the site.

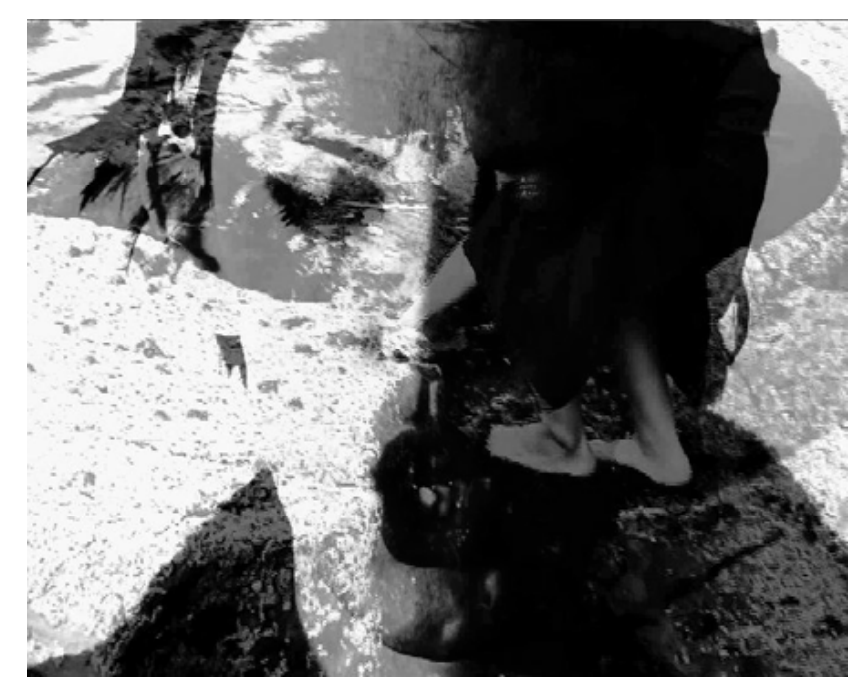

We arrived at the split-phase design to acknowledge the need for deep, rather than incidental, involvement in processes of decision-making, learning, and inquiry. The split-phase design also accommodates the relatively limited bandwidth, power, and screen real estate of the handheld device. Such small devices will continue to improve, so that full video and other later-phase functions could soon become operable in the field. Nevertheless, there would still be reason to maintain the split-phase strategy: most hikers along a nature trail don't want to be preoccupied with computational augmentation of their experiences. They want to enjoy the outdoors at its own scale and in its own terms. Aside from hiking, other applications may have comparable reasons why certain activities would be appropriate to an immediate time and place, while other related activities would be appropriate to a subsequent time and place. Any tool for learning would present the need to design conditions for deep involvement with ideas, which the split-phase strategy can afford.

\section{Smoke Rings}

Another experimental tool, 'Smoke Rings,' combines a handheld computer and desktop application to enable playing 'what-if?' with visualisations of levels and effects of environmental tobacco smoke (ETS) (Clark, 2003; McDonagh, 2003). Players can collect ETS readings and project potential long-term health consequences of sustained exposures. By experimenting with these projections, players may develop notions of risk-taking, their own views of acceptable risk, and understandings of probability more generally. We attempt to cast easily interpretable visual representations in a nonmoralistic, noncompetitive gamelike approach to support and sustain young people's engagement with the data and ideas (Figure 6). 
Figure 6 The portable Smoke Rings monitor would be more convenient as a small wearable device like a wristwatch; nevertheless this initial implementation is useful in identifying further considerations for the genre of split-phase, 'collect and reflect' constructivity designs. Wearers of the device can detect fluctuating smoke levels in various locations and upload the data to a simulator that projects possible long-term health implications of sustained exposures.

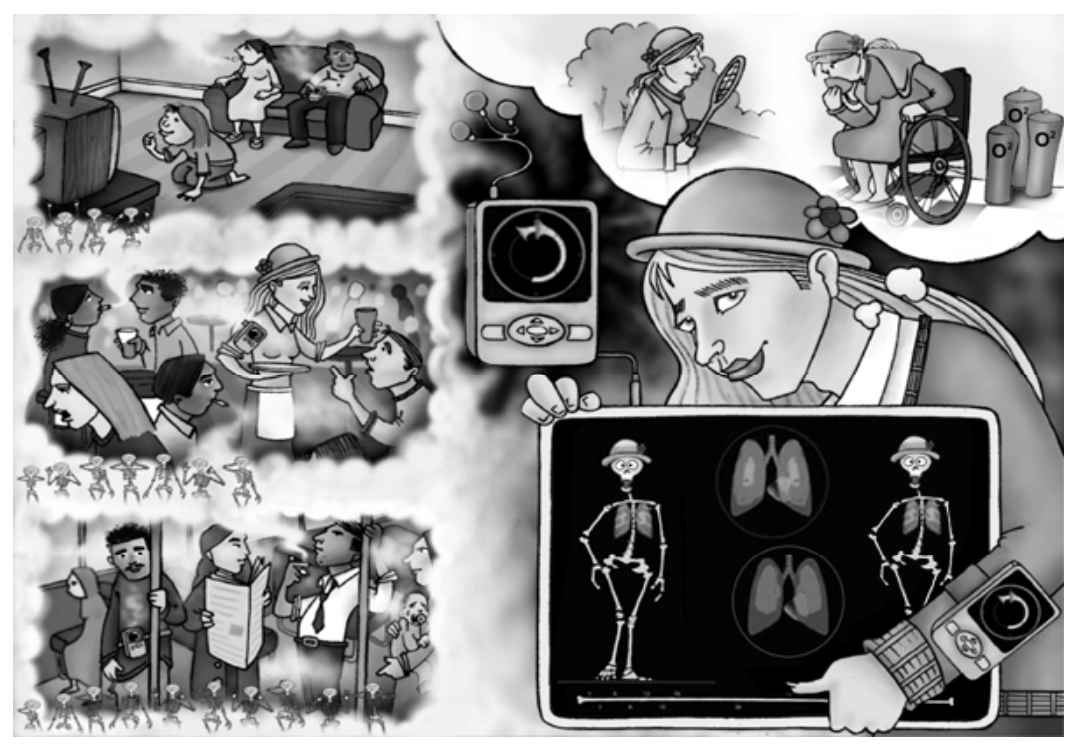

Three chemical sensors connected to a personal digital assistant (PDA) computer detect significant indicators of ETS: carbon monoxide $(\mathrm{CO})$, nitrogen oxides $\left(\mathrm{NO}_{\mathrm{x}}\right)$, and odors associated with tobacco smoke (Figure 7). The highly sensitive semiconductor sensors for $\mathrm{CO}$ and $\mathrm{NO}_{\mathrm{x}}$ detect gas concentrations of $<200 \mathrm{ppm}$. The indium oxide gas sensor can detect many environmental smells and agents but is especially sensitive to nicotine.

Figure 7 Three chemical sensors connected to a Personal Digital Assistant (PDA) computer detect significant indicators of environmental tobacco smoke (ETS): carbon monoxide $(\mathrm{CO})$, nitrogen oxides $\left(\mathrm{NO}_{\mathrm{x}}\right)$, and odors caused by agents such as nicotine.

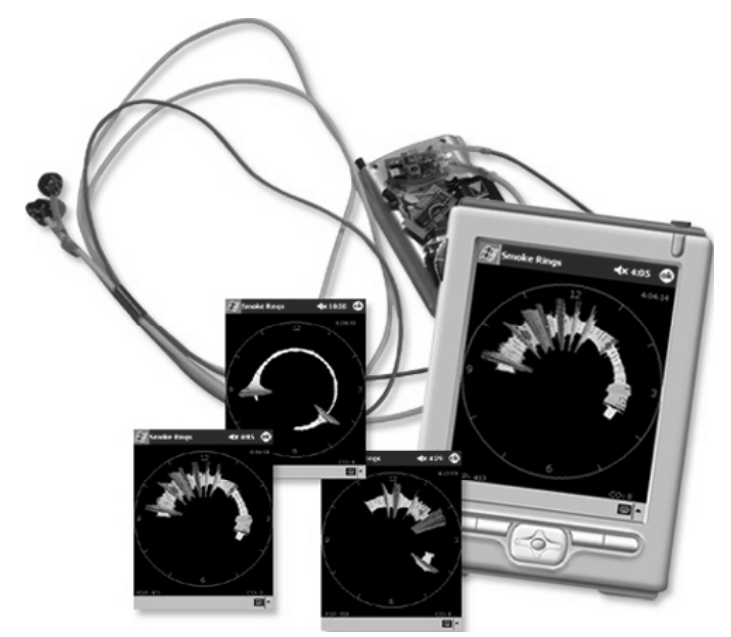


We store the sensor readings and register them in real time by plotting lines around a 12-hour clock-style display (Figures 7 and 8a). The lines get both longer and darker as the chemical levels increase, and narrower and lighter as the levels decrease, creating distinctive 'smoke rings.' This manner of representation is similar to that of a well-known spatiotemporal account of Napoleon's march (Tufte, 1983). It enables easy understanding of changing levels of ETS, and may be a useful representational strategy as such sensing devices continue to shrink and capabilities expand. (For the Smoke Rings device, a small wearable device like a wristwatch would be ideal.)

Detecting fluctuating smoke levels could be useful as you move through various locations during the course of a day. Based on the sensed information, you might change a location (such as moving out of a stale lounge); you might even change an overall lifestyle pattern (such as riding a different train or frequenting a different pub). However, if you want to understand health consequences of sustained ETS exposures, you need to project implications over much longer time scales - not on the order of hours or days but of years and decades.

For this reason, we devised an accompanying simulator that enables seeing possible futures. The simulator accepts uploaded data from the PDA and shows X-ray-style images of smoke-affected lungs. The visualisations are based on the commonly used metric of cigarette equivalency (Figures 8b, 9a, and 11a) (Repace, 1993; Redhead, 1995; Ogden and Martin, 1997; Quan, 1998; Foley-Fisher and Strohecker, in preparation).

We wanted to illustrate potentially serious consequences and acknowledge the many interpretations necessary in translating and extrapolating the highly variable data related to the sensors, environmental conditions, and human physique and physiology. Each of these areas varies widely in ways that complicate data collection and long-term health projections. Therefore, we represented human forms in cartoon fashion, suggesting fictitious outcomes that nevertheless are based in reality. We qualified the simulations with citations and notes about assumptions that we made in developing the projection algorithm. The illustrations here are from an initial sketch-level implementation that would need substantial iteration to generate a workable design (Figures 9b, 10, 11a, and 11b). Nevertheless, the figures are useful in explaining the rationale for the tool.

Figure 8 (a) The programmable PDA stores the sensor readings and registers them in real time as lines plotted around a 12-hour 'clock.' The lines get longer and darker as the chemical levels increase, and narrower and lighter as the levels decrease. (b) An accompanying simulator accepts uploaded data from the PDA and enables X-ray-style visualisations of smoke-affected lungs. The illustrations shown here are from an initial sketch-level implementation.

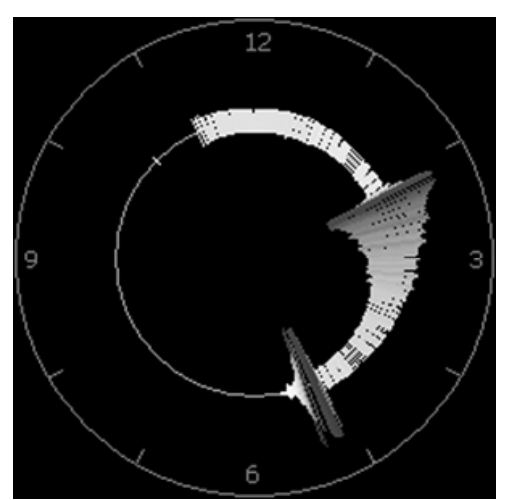

(a)

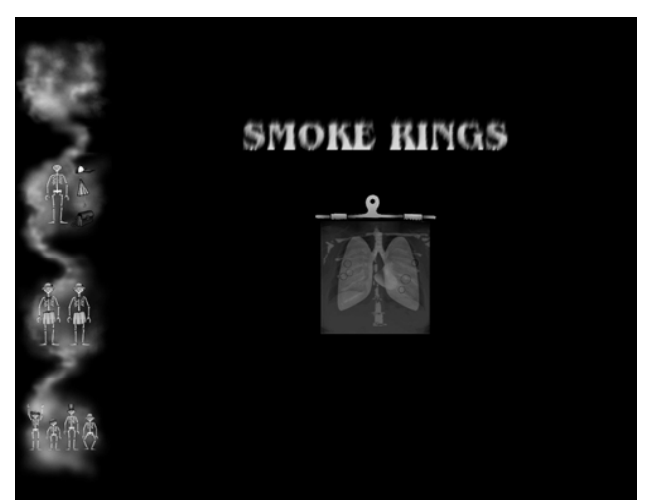

(b) 
Figure 9 (a) Uploaded clock-style logs appear amid a gallery of other recorded data. Players can annotate the recordings with notes such as information about locations in which the recordings were made. A selected log becomes the basis for projecting long-term effects on a person's health, which could result if exposure to particular smoke levels were sustained for many years. (b) The player prepares a character whose body type figures in the projection by selecting a skeleton of a given gender, naming it, and giving it a facial expression and accoutrements. The exaggerated cartoon characters acknowledge the artificial nature of the health projections, necessitated by interpretations we had to make in developing the algorithm for extrapolating and representing the complex and highly variable data.

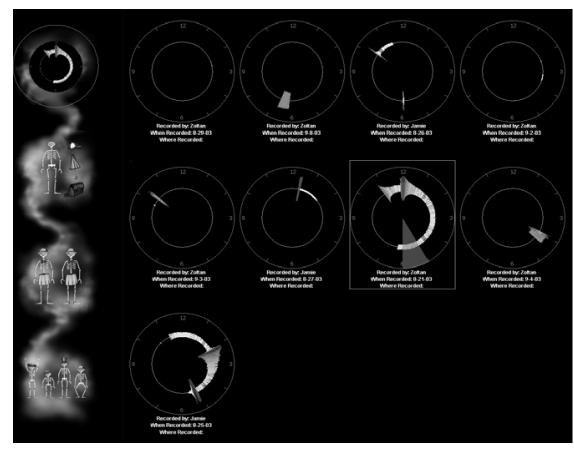

(a)

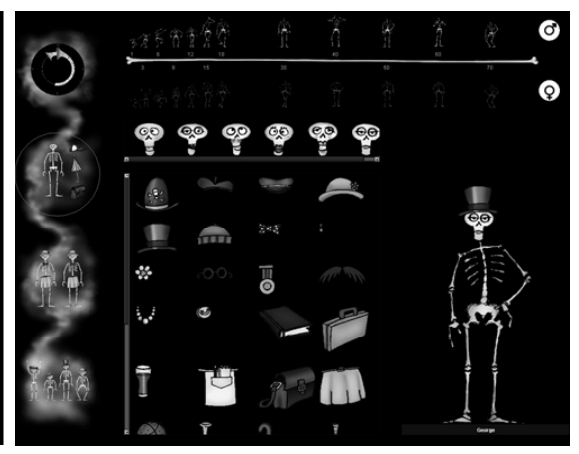

(b)

Figure 10 The player can adorn the character at each of 12 phases of its life. These personal touches can help in identifying the skeleton later and perhaps in promoting the player's identification with the character, thereby enhancing the meaningfulness of the data projections.

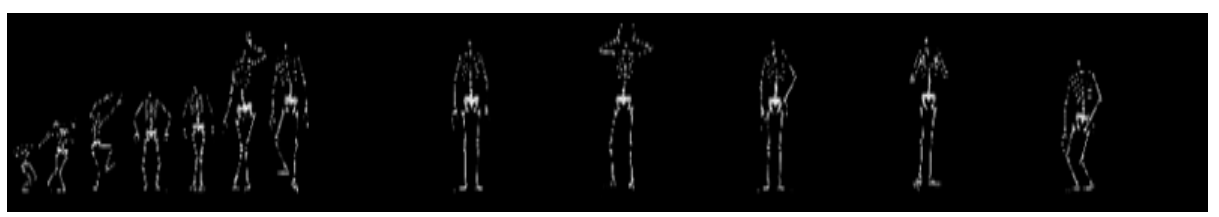

Figure 11 (a) In simulating the projections the software illustrates two versions of the composed character. Each version grows from infancy through old age, with its heart and lungs remaining relatively pink and healthy-looking or getting darker and more textured as the effects of the sustained smoke exposure accumulate through the life span.

Variations in the two representations acknowledge conflicting reports in the scientific literature on the toxicity of ETS. Textual notes provide pointers to such literature and information about the changing character, such as its name and 'age.' (b) Players can save their characters and try them out in simulations with different exposure levels.

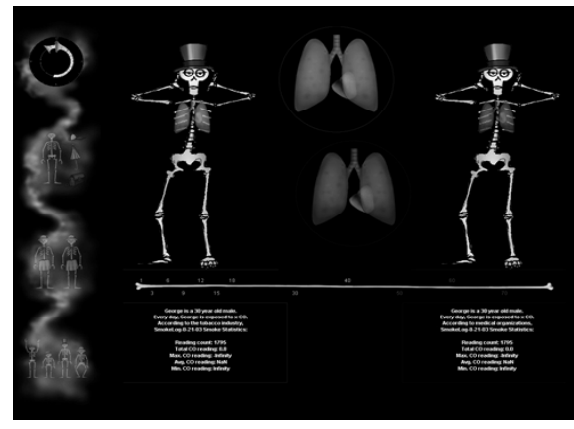

(a)

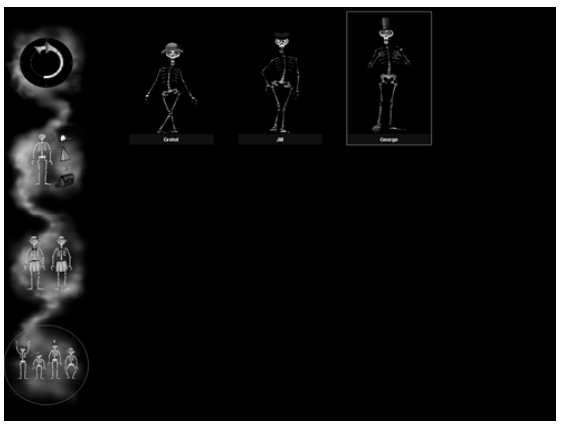

(b) 
Uploaded clock-style data logs appear amid a gallery of other recordings, where the player can annotate information about the site of a given recording (Figure 9a). A selected log becomes the basis for a long-term health projection. In the character composition screen, the player can select a skeleton of a given gender and give it a name and facial expression (Figure 9b). The player can also adorn it with various accessories at each of 12 phases of its life (Figures 9b and 10). These personal touches can help in identifying the skeleton later and perhaps in promoting the player's identification with the character, thereby enhancing the meaningfulness of the data projections.

As the player moves to the comparison screen, the software illustrates two versions of the composed character (Figure 11a). Each version grows from infancy to old age, with its heart and lungs remaining relatively pink and healthy-looking or getting darker and more textured as simulated effects of the sustained ETS exposure accumulate through the life span. The software achieves these effects by adding semi-transparent image layers over situated miniatures and called-out magnifications of the organs.

The literature on the health effects of ETS varies significantly (perhaps, we surmised, depending on whether the funding source for the research is related to an interest of the tobacco or insurance industries). We wanted to acknowledge contradictions in the literature rather than simply coming up with average figures or otherwise reconciling the accounts in singular terms. Therefore, we based the projections on each coarse set of data. The resulting pair of visualisations illustrates a range of extremes with regard to the reported benign or harmful effects of sustained ETS exposures. In this way, the simulation tool amplifies its purpose of visualising scientific data for non-scientists. We hope it may suggest the need for players to read and interpret reported results critically, regardless of their forms or sources.

Players can save their characters and try them out in simulations with different exposure levels (Figure 11a).

The current implementation of Smoke Rings is only a sketch with which we have been able to identify some of the core issues in addressing ETS conditions and implications, as well as more general issues in addressing probabilistic data projection and representation (especially from the perspective of designing for constructive learning). More work is needed to improve the merging of sensor data; detail the characters' demographic and health profiles; refine the constructivity flow, algorithm, and representations in the software simulator; and enable the sending and sharing of logs and constructed characters.

\section{TexTales}

In 'TexTales', the everyday tools of camera and telephone become instruments for developing public opinion, which we consider as a kind of collective learning. We work with people as they create photographs that express views of an issue that concerns them. Topics have included residential displacements in an inner-city neighbourhood, tensions among factions within a rural community, and legislation restricting smoking in public places. 
The participating photographers select and assemble their images into collections of nine, sensitively arranged in a three-by-three grid so as to balance inclusion of different viewpoints and create visually interesting displays (Figures 12 and 13). Photographers formulate a phrase to appear as a text caption beneath each image, in preparation for large-scale projection of the composite display in a public place.

Figure 12 We project TexTales screens large-scale in public places, where passers-by augment the display by sending text messages from their mobile phones. Messages appear as captions under specified photographs. Each new caption replaces its photo's oldest caption and contributes to a larger text-and-image-based discussion.



Figure 13 Participants have ranged in age from young children to senior citizens. Photographers create images to express views of an issue of public concern. Then they select pictures to appear together in clusters of nine. The photographer of a given image invites discussion by creating a 'starter caption' that others can respond to in the ensuing public forum, which involves people of many ages and walks of life.
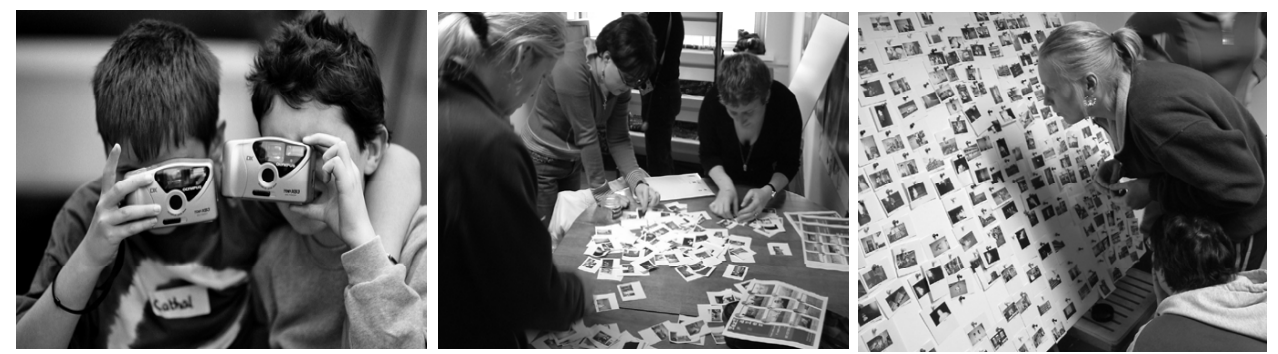
Passers-by continue to augment the display by sending additional captions via the short message service, or SMS text function, of their mobile phones (Ananny et al., 2003a). Each photo can have up to three captions. When a new caption arrives, the set of texts scrolls upward, the oldest caption disappearing at the top as the newest one appears at the bottom. Captions are dynamic horizontally too: though there is a limit on the number of characters in any line of text, captions longer than the width of the photo are still readable as they scroll leftward.

The computer effecting coordination of photos and texts is equipped with a mobile phone subscriber identity module, or SIM card. It has its own cell phone number to which participants send their captions, along with a number identifying the associated photo. Captions appear transient on the display, but the system stores them in a $\log$ file along with the number of the source cell phone, the time when the message appeared, and the number of the photograph addressed. Analyses of these files, along with the participant design methodology of the preparatory workshops and conversations during the installations, provide data for interpretations of people's uses of this composite medium in forming ideas and expressing opinions at personal and public scales (Ananny et al., 2003b; Ananny and Strohecker, in preparation).

We have conducted workshops and public projections with participants ranging in age from teens to senior citizens, gracing an outdoor lot, a train station, conference arenas, and public squares (Figures 14 and 15). Presenting themes have sustained intermodal discourse of issues involving people's deeply held beliefs and often bravely expressed opinions. Pictures and texts about renovations of public-funded housing uncovered fears of lost homes and displacement of families; journal-style documentation of 'a day in the life' among teens in Northern Ireland inevitably evoked - but thankfully enabled - discussion of political and religious tensions; pending legislation to restrict smoking in public places presented an opportunity for young people and their parents, among others, to address the issue of teen smoking and the ETS-related dilemma of individual liberties vs. public health (Figure 16).

Figure 14 By thinking with the pictures and texts, and with relations among ideas expressed in these combined forms, participants debate issues through 'intermodal' discussion. The dynamic projections last for several hours, feeding and reflecting the larger discussion as people come and go.
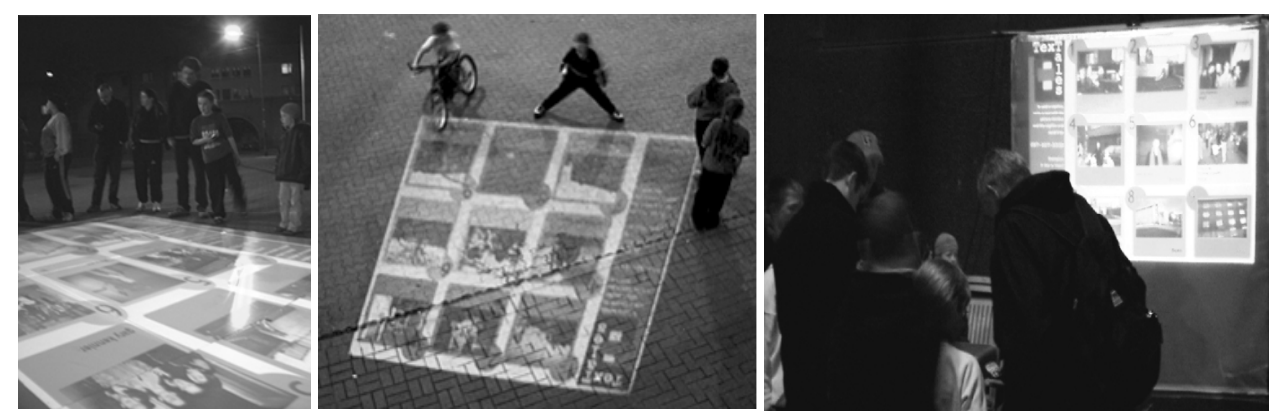
Figure 15 Installations have supported exchanges of views about residential displacements in an inner-city neighbourhood, tensions among factions within a rural community, and legislation restricting smoking in public places.
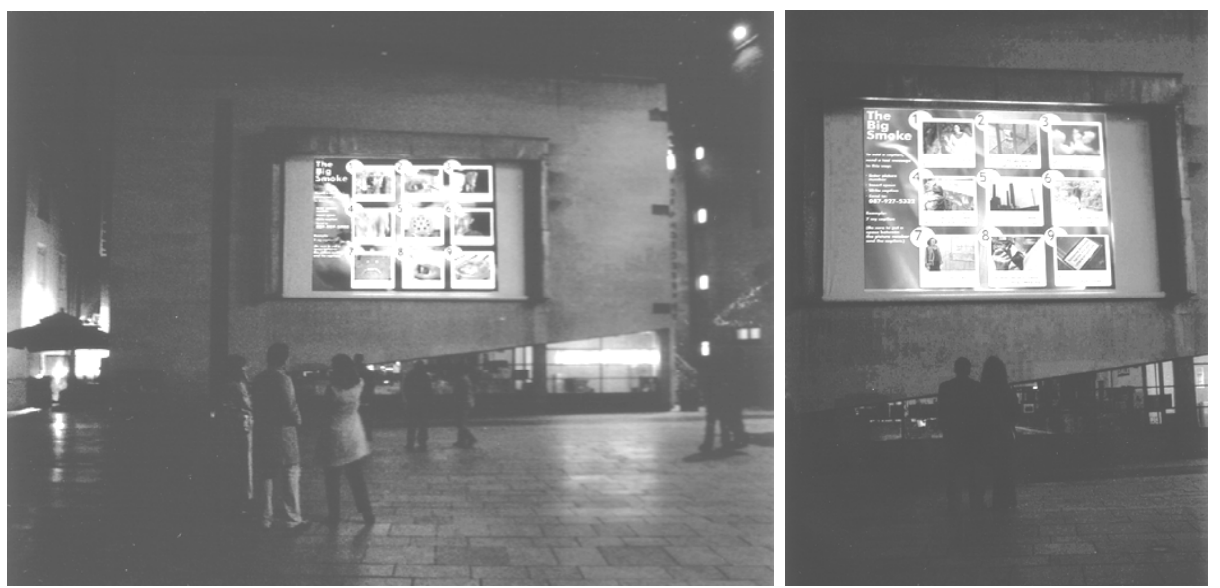

Figure 16 As with the Smoke Rings project, our goal was not to take a stand on smoking issues but to provoke and support discussion of questions about ETS, teen smoking, and anti-smoking legislation.
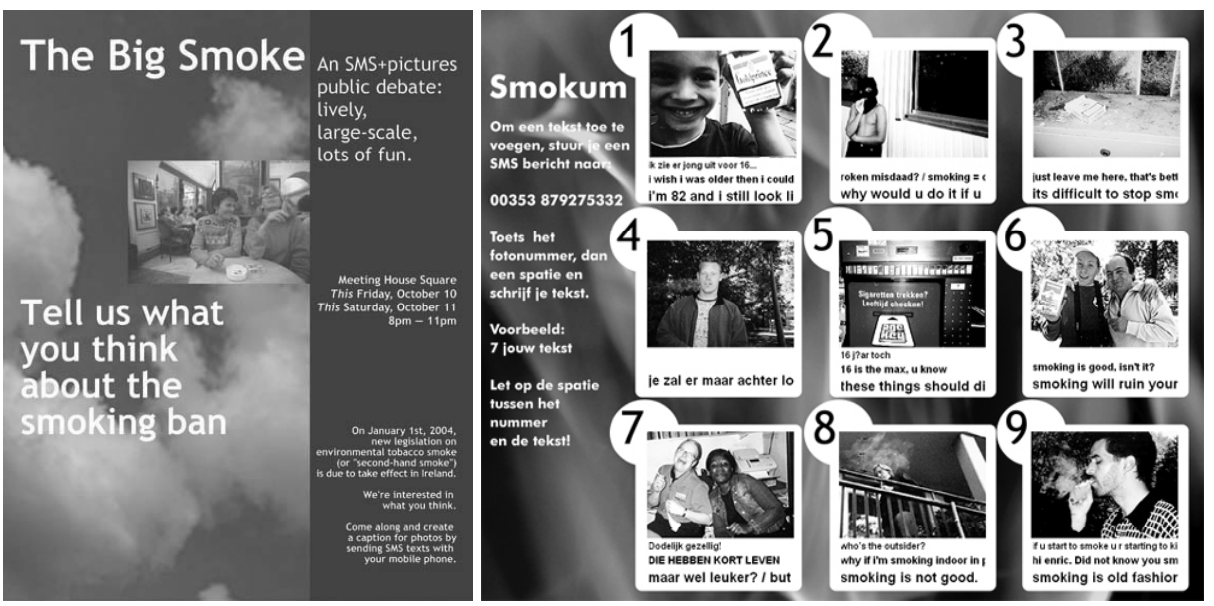

As mobile telephony continues to evolve, more people will have camera-phones with which they can communicate both verbally and visually. With the advent of disposable cameras and small digital camcorders, we have already seen changes in journalistic practice: documentation of police brutality, plane crashes, and other newsworthy events often comes from citizens who happen to be near the event rather than from professional journalists.

The trend will continue as technologies advance and become more ubiquitous, and as people use the increasing range of functionalities to develop 'intermodal literacies.' TexTales suggests needs and possibilities for formulation of new journalistic practices, new kinds of polling methods, and new situations for collective learning such as within ad hoc communities of interest. 


\section{Conclusion}

The 'collect and reflect' interfaces described here aim to complement and enrich interactions in an immediate time and place with constructive interactions through partnered devices in a subsequent, related context. In the case of Nature Trailer, a rich set of location-based information supports decision-making, augments an outdoor experience, and shapes a later, more relaxed encounter with digital narratives. In the case of Smoke Rings, the later phase of interactivity provides glimpses into possible futures through probabilistic data projection. In the case of TexTales, each phase of interactivity supports learning about issues of public concern both individually and collectively.

TexTales also points to changes in professional practices as people use increasingly pervasive technologies for communicating and increasingly accessible tools for organising, editing, and publishing media. People can form and express ideas and opinions individually and within emergent communities of interest, potentially challenging centralised systems of content creation and distribution (Strohecker, 2003).

As technologies for sensing become increasingly pervasive, we can envision a similar change occurring within medical industries. Centralised systems may give way to more localised control as individuals, families, and communities increasingly take charge of their own healthcare and well-being, and that of the environments in which they live. Perhaps this could also occur in educational contexts, as people increasingly take charge of their own learning and development, and that of the communities in which they live (Illich, 1972).

\section{Acknowledgements}

The work described here emerged through contributions by members of the Everyday Learning (EL) research group at Media Lab Europe (MLE) in Dublin, Ireland. Nature Trailer was a collaborative project with MLE's Story Networks group, led by Glorianna Davenport; Alison Wood of Story Networks and Brendan Donovan of Everyday Learning spearheaded the effort, and Deirdre Williams helped with implementation. Discussions of 'e-Sense' at MLE led to the thinking that generated Smoke Rings, which has brought together the skills and talents of many in Everyday Learning, especially Jamie Rasmussen, Matt Karau, and Zoltan Foley-Fisher; Bronagh O'Hanlon, Mike Ananny, Brendan Donovan, Mauro Cherubini, and Rukshana Cader also contributed. TexTales involved many players within and outside of EL/MLE: EL member Mike Ananny spearheaded the effort, working with Brendan Donovan and Jamie Rasmussen of EL and Kathleen Biddick of the Fulbright programme and the University of Notre Dame; Mike also coordinated among teens and adults who debated via TexTales, and among organisations that provided venues and supports for the public projections: The Ark, Temple Bar Properties, Young at Art, BBC Northern Ireland, Virtueel Platform, and Intel Computer Clubhouses. TexTales has led us to discussions of multimodal forms and intermodal literacies, involving Sile O'Modhrain of MLE; Helen Doherty of Dun Laoghaire Institute of Art, Design and Technology; and the newest members of EL, Andrea Taylor and Karen Martin, who also helped with demonstrations and other descriptions of the projects. We are grateful to Idit Harel, Allison Druin, and Deirdre Butler, who helped bring the projects together for the 2004 Interaction Design and Children conference. 


\section{References}

Ananny, M. and Strohecker, C. (In preparation) Forms and Forums for Developing Public Opinions.

Ananny, M., Ronan, J. and Durand, M. (2003a) The Big Smoke, Dublin: The Ark and Media Lab Europe.

Ananny, M., Strohecker, C. and Biddick, K. (2003b) 'Shifting scales on common ground: developing personal expressions and public opinions', International Journal of Continuing Engineering Education and Life-Long Learning.

Benjamin, W. (2004/1936) 'The work of art in the age of mechanical reproduction', in D.S. Ferris (Ed.) The Cambridge Companion to Walter Benjamin (Cambridge Companions to Literature), Cambridge University Press.

Berger, J. (1990/1973) Ways of Seeing, New York, NY: Penguin Press.

Birdwhistell, R.L. (1970) Kinesics and Context: Essays on Body Motion Communication, University of Pennsylvania Press.

Clark, M. (2003) 'Scientists build “passive smoke” detector', ElectricNews.net, 27 May.

Dondis, D.A. (1973) A Primer of Visual Literacy, Cambridge, MA: MIT Press.

Donovan, B., Wood, A., Davenport, G. and Strohecker, C. (2003) 'Nature trailer: physically navigate stories in the wild', Design Methods for Ubiquitous Computing in the Wild Workshop, Mobile and Ubiquitous Multimedia Conference, Norrkoping, Sweden.

Donovan, B., Wood, A., Williams, D., Strohecker, C. and Davenport, G. (2004) 'Nature trailer update', Technical Note, Media Lab Europe.

Foley-Fisher, Z. and Strohecker, C. (2005) 'An approach to the presentation of information from multiple sensors', Media Lab Europe Technical Report, Dublin.

Garrett, J.J. (2002) The Elements of User Experience: User-Centered Design for the Web, New York: American Institute of Graphic Arts, Indianapolis: New Riders Publishing.

Harel, I. and Papert, S. (Eds.) (1991) Constructionism, Norwood, NJ: Ablex.

Illich, I. (1972) Tools for Conviviality, New York: Harper and Row.

Jacobson, B. (Ed.) (1999) Information Design, Cambridge, MA: MIT Press.

Kafai, Y.B. and Resnick, M. (Eds.) (1996) Constructionism in Practice: Designing, Thinking, and Learning in a Digital World, Mahwah, NJ: Lawrence Erlbaum.

Lakoff, G. and Johnson, M. (1980) Metaphors We Live By, University of Chicago Press.

Lewkowicz, D.J. (1999) 'The development of temporal and spatial intermodal perception', in G. Aschersleben, T. Bachman and J. Musseler (Eds.) Cognitive Contributions to the Perception of Spatial and Temporal Events, Elsevier Science.

McCloud, S. (1993) Understanding Comics, New York: Harper Collins.

McDonagh, M. (2003) 'New device will add fuel to passive smoking debate', Irish Independent, 27 May.

McLuhan, M. (1964) Understanding Media: The Extensions of Man.

Oakley, I. and O'Modhrain, S. (2003) 'Cross-modal perception of motion-based visual-haptic stimuli', International Multisensory Research Forum.

Ogden, M. and Martin, P. (1997) 'The use of cigarette equivalents to assess environmental tobacco smoke exposure', Environ International, Vol. 23, No. 1, pp.123-138.

O'Modhrain, S. (2004) 'Touch and go - designing haptic feedback for a hand-held mobile device', BT Technology Journal, Vol. 22, p.4.

Papert, S. (1980) Mindstorms: Children, Computers, and Powerful Ideas, New York: Basic Books.

Picard, R.W., Papert, S., Bender, W., Blumberg, B., Breazeal, C., Cavallo, D., Machover, T., Resnick, M., Roy, D. and Strohecker, C. (2004) 'Affective learning - a manifesto', BT Technology Journal, Vol. 22, No. 4, pp.253-269. 
Quan, C. (1998) 'Comparing environmental tobacco smoke intake among restaurant workers and adults at home', Berkeley McNair Journal, http://www-monair.berkeley.edu/98journal/cquan/

Redhead, C. (1995) 'Environmental tobacco smoke and lung cancer risk', Congressional Research Service, pp.95-115, http://www.tobacco.org/resources/documents/9511crsepa.html

Repace, J.L. (1993) Tobacco Smoke Pollution, in Nicotine Addiction, Principles and Management, in T. Orleans and A.H. Lowrey (Eds.) New York: Oxford University Press.

Resnick, M., Berg, R. and Eisenberg, M. (2000) 'Beyond black boxes: bringing transparency and aesthetics back to scientific investigation', Journal of the Learning Sciences, Vol. 9, No. 1, pp.7-30.

Schön, D.A. (1983) The Reflective Practitioner, New York: Basic Books.

Schön, D.A. (1992) 'Designing as reflective conversation with the materials of a design situation', Knowledge-Based Systems, Vol. 5, No. 1, pp.3-13.

Shedroff, N. (2001) Experience Design 1, Indianapolis: New Riders Publishing.

Strohecker, C. (1996) 'Design of an environment for learning about topology and learning about learning', Proceedings of the Second International Conference on the Learning Sciences, Association for the Advancement of Computing in Education.

Strohecker, C. (2003) 'Whole world in their hands', The Learning Citizen, European Commission Information Society Technologies, Vol. 6, pp.6-8.

Strohecker, C. (2004) 'Evolving literacy: crafting messages for senses, sensibilities, and sense-making', Vodaphone Group Receiver, No. 10, http://www.natural-reality.de/receiver/10 /articles/index 10. html

Strohecker, C. and Ananny, M. (2003) 'Constructing intermodal literacies', Proceedings of ACM Technology Enhanced Learning.

Strohecker, C. and Butler, D. (2004) 'The informal informing the formal in forming new models of learning', Proceedings of ACM Interaction Design and Children.

Strohecker, C. and Slaughter, A.H. (2000) 'Kits for learning and a kit for kitmaking', Proceedings of ACM Special Interest Group on Computer-Human Interaction.

Strohecker, C. and Slaughter, A.H. (2001) 'A framework for microworld-style construction kits', Proceedings of EdMedia: World Conference on Educational Multimedia, Association for the Advancement of Computing in Education.

Suchman, L. (1987) Plans and Situated Actions, Cambridge, UK: Cambridge University Press.

Taylor, A., Donovan, B., Foley-Fisher, Z. and Strohecker, C. (2004) 'Time, voice, and joyce', Proceedings of the First ACM Workshop on Story Representation, Mechanism and Context, ACM Multimedia, pp.67-70.

Tufte, E.R. (1983) The Visual Display of Quantitative Information, Cheshire, CT: Graphics Press.

Turkle, S. (1984) The Second Self: Computers and the Human Spirit, New York: Simon and Schuster.

Turkle, S. and Papert, S. (1990) 'Epistemological pluralism: styles and voices within the computer culture', Signs, Chicago University Press, Vol. 16, No. 1.

Winograd, T. et al. (1996) Bringing Design to Software, Reading, MA: Addison-Wesley.

Wood, A., Davenport, G., Donovan, B. and Strohecker, C. (2004) 'Stories for remote place: content, structure, device, trials', Proceedings of International Cultural Heritage Informatics. 